\title{
Role of obesity in gestational hypertension in primigravidae women: A case control study in Shadegan, Iran
}

\author{
Leila Moftakhar ${ }^{1}$, Masoud Solaymani-Dodaran*2, Bahman Cheraghian ${ }^{3}$ \\ Received: 31 Aug 2017 \\ Published: 28 Oct 2018
}

\begin{abstract}
Background: Gestational hypertension is a serious problem among pregnant women in Shadegan. This study was conducted to estimate the prevalence and risk factors of gestational hypertension in these women.

Methods: In this study, the prevalence of gestational hypertension was estimated. Then, a case-control study was performed on 310 pregnant women with gestational hypertension and 930 healthy pregnant women in 2014. Multiple logistic regression was used to explore the possible risk factors. The analysis was repeated in a subgroup of primigravidae women to identify the risk factors that led to gestational hypertension.

Results: The prevalence of gestational hypertension among pregnant women in Shadegan was 9.6\%. Moreover, multiple logistic regression of all pregnant women showed that obese pregnant women were 1.79 times $(\mathrm{OR}=1.79 ; 95 \% \mathrm{CI}=1.19-2.71 ; \mathrm{p}<0.005)$ more likely to have gestational hypertension. Overweight and obese primigravidae women were $2.13(\mathrm{OR}=2.1 ; 95 \% \mathrm{CI}=1.031-4.34$; $\mathrm{p}<0.041)$ and $4.8(\mathrm{OR}=2.4 ; 95 \% \mathrm{CI}=1.13-5.16 ; \mathrm{p}<0.022)$ times more likely to have gestational hypertension than women with normal BMI, respectively. Age, education, history of gestational hypertension, and type of residential area of the primigravidae women were also significant factors.

Conclusion: BMI is the most important risk factor for gestational hypertension. More focus needs to be laid on this issue to raise awareness on the preservation of proper BMI before pregnancy, which can help decrease gestational hypertension.
\end{abstract}

Keywords: Gestational hypertension, Pregnancy, Risk factor, Shadegan, Iran

Conflicts of Interest: None declared

Funding: None

\section{*This work has been published under CC BY-NC-SA 1.0 license.}

Copyright $₫$ Iran University of Medical Sciences

Cite this article as: Moftakhar L, Solaymani-Dodaran M, Cheraghian B. Role of obesity in gestational hypertension in primigravidae women: A case control study in Shadegan, Iran. Med J Islam Repub Iran. 2018 (28 Oct);32:104. https://doi.org/10.14196/mjiri.32.104

\section{Introduction}

Hypertension is one of the most important complications that may occur during pregnancy. Hypertensive disorders during pregnancy are classified as chronic hypertension, preeclampsia, eclampsia, and preeclampsia superimposed on chronic hypertension (1).

Chronic hypertension in pregnancy is defined (2) as a minimum of $140 \mathrm{mmHg}$ systolic or $90 \mathrm{mmHg}$ diastolic blood pressure after the 20th week of pregnancy or the first 24 hours after delivery. If it is associated with proteinuria higher than $300 \mathrm{~mm}$, it is called preeclampsia (2). The incidence of preeclampsia in pregnancies is $6 \%$

\footnotetext{
Corresponding author: Dr Masoud Solaymani-Dodaran, solaymani.m@iums.ac.ir

1. Department of Epidemiology, School of Health, Iran University of Medical Sciences, Tehran, Iran

2. Minimally Invasive Surgery Research Center, Iran University of Medical Sciences, Tehran, Iran

3. Research Center for Infectious Diseases of Digestive System, Department of Biostatistics and Epidemiology, School of Public Health, Ahvaz Jundishapur University of Medical Sciences, Ahvaz, Iran
}

and that of eclampsia is $2 \%$ to $5 \%$. Hypertensive disorders of pregnancy occur in $5 \%$ to $10 \%$ of all pregnancies and contribute to a major proportion of maternal morbidities and mortalities (2). The pre valence of this disorder has been estimated at around 3\% in the United States, $7.8 \%$ in Tizhchi (3), 6.9\% in Haryana (4), 6/1\% in Ghana (1), and $1.9 \%$ South Asia (5). However, in Iran, it has a prevalence of $3.4 \%$ in Iranshahr (6) and $6.4 \%$ in Tehran (7).

Despite decades of extensive research, it is yet unclear how pregnancy can aggravate hypertension (2). While preeclampsia has been accepted as a preventable and

$\uparrow$ What is "already known" in this topic:

Hypertension is one of the most important complications that may occur during pregnancy. It is defined as a minimum of $140 \mathrm{mmHg}$ systolic or $90 \mathrm{mmHg}$ diastolic blood pressure after the 20th week of pregnancy or the first 24 hours after delivery.

$\rightarrow$ What this article adds:

This study revealed that obesity was the main cause of gestational hypertension in primigravidae women. 
controllable disease (8), identified risk factors for gestational hypertension are obesity, multiple pregnancies, maternal age over 35 years, race and ethnicity, environmental factors, poverty, and chronic hypertension (6), having a history of preeclampsia (9), low education level, having a sister with a history of preeclampsia, exposure to diethylstilbestrol, interval between current and previous pregnancy, history of preterm delivery, and inadequate prenatal care (6).

Gestational hypertension is one of the most common causes of hospitalization among pregnant women, and if other symptoms of preeclampsia also occur, it can be lifethreatening in both the mother and the fetus. Moreover, this disorder imposes high costs on the health care system and causes stress in patients. This study was conducted to determine the prevalence and the most important risk factors of gestational hypertension in primigravidae and pregnant women in Shadegan, Iran.

\section{Methods}

\section{Data}

This unmatched case-control study was conducted among pregnant women receiving prenatal care in Shadegan in 2014. The research council and ethics committee of Iran University of Medical Sciences approved the study's proposal. The researcher visited Shadegan's health centers to estimate the prevalence of gestational hypertension among pregnant women by collecting data on the total number of pregnant women and the number of pregnant women with gestational hypertension in 2014.

All eligible pregnant women with gestational hypertension (310) were selected as the case group and a random sample of healthy pregnant women (930 participants) from Shadegan were selected as the control group.

Women who had a minimum of $140 \mathrm{mmHg}$ systolic or $90 \mathrm{mmHg}$ diastolic blood pressure after the 20th week of pregnancy or during the first 24 hours after delivery were included in the study. Inclusion criterion for the control group was not having gestational hypertension (2). Those with heart disease were excluded from the study.

After selecting the case and control groups, the researchers visited urban and rural health centers in Shadegan to collect data and complete the checklist by extracting health information from the existing health care file filled during pregnancy.

A predesigned checklist was used that consisted of demographic information such as, age, type of residential area, education level, and occupation. Furthermore, the following information about pregnancy was also collected: history of previous pregnancies, gestational age, parity, body mass index, gravidity, gestational hypertension, abortion, multiple pregnancies, interval between previous and current pregnancy, and latest method of contraception used.

\section{Statistical analysis}

Data were analyzed using SPSS v. 22. After examining all pregnant women to identify the risk factors, the analysis was repeated for a subgroup of primigravidae women to identify the variables that led to gestational hypertension.

Chi-square test was used to evaluate the association between qualitative variables and compare them in the 2 groups. In addition, independent $t$ test was used to compare quantitative variables between the 2 groups. Univariate logistic regression analysis was used to find the probable risk factors for gestational hypertension. Multiple logistic regression analysis (backward stepwise method with maximum likelihood ratio approximation) was used to identify the potential risk factors that cause gestational hypertension. Then, variables that were significant in the univariate logistic regression model were entered in the multiple logistic regression model. The results of univariate and multiple logistic regression analyses were presented with odds ratio and $95 \%$ confidence interval.

\section{Results}

Among the total 4015 pregnant women, 387 had gestational hypertension and the prevalence of gestational hypertension was estimated to be $9.6 \%$ (95\%CI: $8.74-$ 10.59) among pregnant women in Shadegan. The mean BMI among pregnant women with gestational hypertension was significantly higher than those without gestational hypertention (28.28 \pm 5.88 vs. 25.87 \pm 4.77 , $\mathrm{p}<0.0001)$. The mean BMI among primigravidae women with and without gestational hypertension was $27.53 \pm 5.16$ and $24.42 \pm 4.38$, respectively, and it was statistically significant $(\mathrm{p}<0.0001)$. Pregnant women with gestational hypertension were older (mean $\pm \mathrm{SD}$ age: $28.95 \pm 5.88$ years) than those without hypertension (mean \pm SD age: $27.36 \pm 5.84$ years; $p<0.0001)$ Also, pregnant women with gestational hypertension had the gravidity and parity higher than those in the control group (Table 1).

On examining the relationship between gestational hypertension and various factors without controlling the confounding factors in pregnant women, we found statistically significant associations between the risk of gestational hypertension and pregnant women's age, education, parity, BMI, gravidity, and history of hypertension in a previous pregnancy (Table 2).

Finally, after controlling for the potential confounding variables in all pregnant women, we observed that with each year increase in age, the risk of gestational hypertension increased by 1.037 times $(\mathrm{OR}=1.037 ; 95 \%$ $\mathrm{CI}=1-1.069 ; \mathrm{p}<0.002)$. Moreover, pregnant women with BMI in the obese range were 1.79 times more likely to have gestational hypertension than those with normal BMI $(\mathrm{OR}=1.79 ; 95 \% \mathrm{CI}=1.19-2.71 ; \mathrm{p}<0.005)$. The risk of gestational hypertension in women with a history of hypertension in a previous pregnancy was about 10 times higher than those without a history of gestational hypertension $(\mathrm{OR}=9.87 ; 95 \% \mathrm{CI}=5.88-16.55 ; \mathrm{p}<0.0001)$. Moreover, women with high school education were 2.4 times $(\mathrm{OR}=2.4 ; 95 \% \mathrm{CI}=1.13-5.16 ; \mathrm{p}<0.022)$ and those with secondary school education were 2.1 times more likely than women with academic education $(\mathrm{OR}=2.1$; $95 \% \mathrm{CI}=1.031-4.34 ; \mathrm{p}=0.041)$ to have gestational 
Table 1. The relationship between quantitative and qualitative variables in the 2 groups of pregnant women: Those with gestational hypertension and those without gestational hypertenson in Shadegan in 2014

\begin{tabular}{|c|c|c|c|c|}
\hline 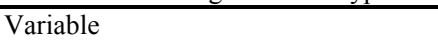 & Category & Case $(\mathrm{n}=310)$ & Control $(\mathrm{n}=930)$ & $\mathrm{p}^{* * *}$ \\
\hline Age (year) & - & $28.95 \pm 5.88^{*}$ & $27.36 \pm 5.84$ & 0.0001 \\
\hline BMI & - & $28.28 \pm 5.88$ & $25.87 \pm 4.77$ & 0.0001 \\
\hline Gravidity & - & $2.91 \pm 1.61$ & $2.65 \pm 1.47$ & 0.012 \\
\hline Parity & - & $1.65 \pm 1.46$ & $1.44 \pm 1.32$ & 0.015 \\
\hline $\begin{array}{l}\text { Interval between previous and current } \\
\text { pregnancy }\end{array}$ & - & $36.78 \pm 26.36$ & $35.74 \pm 25.36$ & 0.598 \\
\hline \multirow[t]{5}{*}{ Body mass index } & & - & - & 0.0001 \\
\hline & $=<18.49$ & $4(1.3)^{* *}$ & $25(2.7)$ & - \\
\hline & $18.5-24.9$ & $91(29.4)$ & $409(44)$ & - \\
\hline & $25-29.99$ & $102(32.9)$ & $331(35.6)$ & - \\
\hline & $>=30$ & $113(36.5)$ & $165(17.7)$ & - \\
\hline \multirow{3}{*}{$\begin{array}{l}\text { History of } \\
\text { hypertension in pregnancy }\end{array}$} & & - & - & 0.0001 \\
\hline & No & $168(54.2)$ & $684(14.6)$ & - \\
\hline & Yes & $65(21)$ & $27(2.9)$ & - \\
\hline \multirow[t]{6}{*}{ Education } & & - & - & 0.0001 \\
\hline & Illiterate & $60(19.4)$ & $136(14.6)$ & - \\
\hline & Primary school & $125(40.3)$ & 2993(31.5) & - \\
\hline & Secondary school & $55(17.7)$ & $166(17.8)$ & - \\
\hline & High school & $47(15.2)$ & $246(26.5)$ & - \\
\hline & Academic & $23(7.4)$ & $89(9.6)$ & - \\
\hline \multirow[t]{3}{*}{ Type of residential area } & & - & - & 0.008 \\
\hline & Urban & $185(59.7)$ & $555(59.7)$ & - \\
\hline & Rural & $125(40.3)$ & $375(40.6)$ & - \\
\hline \multirow[t]{3}{*}{ History of abortion } & & - & - & 0.183 \\
\hline & No & $199(64.5)$ & $632(68)$ & - \\
\hline & Yes & $34(11)$ & $79(8.5)$ & - \\
\hline \multirow[t]{4}{*}{ Occupation } & & - & - & 0373 \\
\hline & Housewife & $299(96.5)$ & $890(95.7)$ & - \\
\hline & Self-employed & $4(1.3)$ & $7(0.7)$ & - \\
\hline & Employee & $7(2.3)$ & $33(3.5)$ & - \\
\hline \multirow[t]{7}{*}{ Latest method of contraception used } & & - & - & 0.378 \\
\hline & Combined pill & $82(26.5)$ & $282(30.3)$ & - \\
\hline & Minipills & $2(0.6)$ & $13(1.04)$ & - \\
\hline & Condom & $31(10)$ & $100(10.8)$ & - \\
\hline & Injection & $4(1.3)$ & $7(0.8)$ & - \\
\hline & Natural Methods & $71(22.9)$ & $220(23.7)$ & - \\
\hline & None & $120(38.7)$ & $308(33.1)$ & - \\
\hline \multirow[t]{3}{*}{ Multiple pregnancy } & & - & - & 0.745 \\
\hline & No & 302(97.2) & 909(97.7) & \\
\hline & Yes & $8(2.6)$ & $21(2.3)$ & \\
\hline \multicolumn{5}{|c|}{${ }^{*}$ Mean \pm SD, ${ }^{* *} \mathrm{n}(\%),{ }^{* * *}$ Student $\mathrm{t}$-test for continuous variables and Chi-Square for categorical variables } \\
\hline \multicolumn{5}{|c|}{ Table 2. Results of univariate and multivariate regression analyses of risk factors in all the pregnant women of Shadegan in 2014} \\
\hline Variable & & & OR $(95 \% \mathrm{CI})$ & 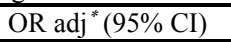 \\
\hline \multirow[t]{3}{*}{ Age } & & & $1.04(1.02-1.06)$ & $1.03(1.006-1.06)$ \\
\hline & & & - & - \\
\hline & & Academic & 1 & 1 \\
\hline \multirow[t]{4}{*}{ Education } & & High school & $1.7(0.98-2.96)$ & $2.42(1.13-5.16)$ \\
\hline & & Secondary school & $1.65(0.99-2.73)$ & $2.11(1.03-4.34)$ \\
\hline & & Primary school & $1.28(0.73-2.22)$ & $2.03(0.93-4.39)$ \\
\hline & & Illiterate & $0.73(0.42-1.28)$ & $0.92(0.42-2.04)$ \\
\hline \multirow{2}{*}{\multicolumn{2}{|c|}{ History of hypertension in previous pregnancy }} & & $9.8(6.06-15.83)$ & $9.87(5.88-16.55)$ \\
\hline & & $18.5-25$ & $\overline{1}$ & $\begin{array}{ll}- \\
1\end{array}$ \\
\hline \multirow{3}{*}{ Body mass index } & & $=<18.5$ & $0.71(0.24-2.11)$ & $0.83(0.23-2.99)$ \\
\hline & & $25-29.99$ & $1.38(1-1.93)$ & $0.86(0.57-1.28)$ \\
\hline & & $>=30$ & $3.07(2.21-4.28)$ & $1.79(1.19-2.71)$ \\
\hline
\end{tabular}

hypertension. There was no statistically significant association between other variables entered in the multiple logistic regression and the risk of gestational hypertension (Table 2).

Primigravidae women were analyzed separately to identify the variables that led to gestational hypertension in the first pregnancy. Multiple logistic regression analysis of these women revealed that the risk of gestational

hypertension was 2 times more in women who lived in urban areas than in those who lived in rural areas $(\mathrm{OR}=1.99 ; 95 \% \mathrm{CI}=1.05-3.61 ; \mathrm{p}<0.022)$. Furthermore, compared to women with normal BMI, the risk of gestational hypertension was 5 times greater in primigravidae women with BMI in the obese range $(\mathrm{OR}=4.88 ; 95 \% \mathrm{CI}=2.35-10.12 ; \mathrm{p}<0.0001)$ and 2.1 times greater in those with BMI in the overweight range 


\begin{tabular}{|c|c|c|c|}
\hline Variable & & OR $(95 \% \mathrm{CI})$ & $\mathrm{OR} \mathrm{adj}^{*}(95 \% \mathrm{CI})$ \\
\hline \multicolumn{4}{|c|}{ Type of residential area } \\
\hline & Rural & 1 & 1 \\
\hline & Urban & $2.16(1.22-3.81)$ & $1.93(1.07-3.5)$ \\
\hline \multirow{5}{*}{ Body mass index } & & - & - \\
\hline & $18.5-25$ & 1 & 1 \\
\hline & $=<18.5$ & $0.76(0.08-6.42)$ & $0.81(0.4-77.05)$ \\
\hline & $25-29.99$ & $2.25(1.19-4.24)$ & $2.1(1.1-4.02)$ \\
\hline & $>=30$ & $5.73(2.83-11.61)$ & $4.91(2.36-1.1)$ \\
\hline
\end{tabular}

*Adjusted for BMI, age and type of residential area (Education was not significant in univariate regression analyses and did not enter the final model.)

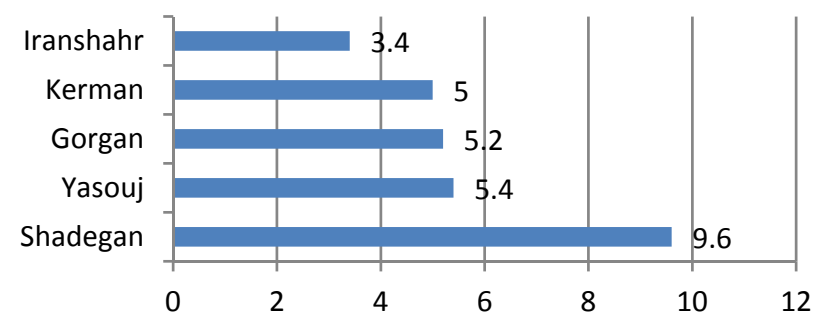

Fig. 1. The prevalence of gestational hypertension in percent different cities of Iran

$(\mathrm{OR}=2.1 ; 95 \% \mathrm{CI}=1.12-4.05 ; \mathrm{p}<0.021)($ Table 3$)$

\section{Discussion}

The prevalence of gestational hypertension was $9.6 \%$ in pregnant women in Shadegan. This figure is much higher than the results reported by the many studies conducted in Iran and around the world $(3,6)$ (Fig. 1), and it may be attributed to the women's lifestyle or nutrition.

In this study, after controlling for possible confounding factors, we found that only BMI and residential area remained significant factors in the final model in primigravidae women. Obese primigravidae pregnant women were 5 times more likely to develop gestational hypertention compared to those with normal weight (Table 3). BMI, age, history of hypertension in a previous pregnancy and education level were risk factors for gestational hypertension. When we examined all pregnant women in the study, we found that the risk of gestational hypertension in obese pregnant women was reduced from 3 to 1.8 times after adjusting for confounding factors. This decrease was due to the confounding effect of history of hypertension in the previous pregnancy. After performing the analysis without the confounding factor of history of hypertension in the previous pregnancy, we found no changes in other variables.

BMI was identified as the most important factor causing gestational hypertension in primigravidae. Before controlling for BMI and residential area, the strength of association was close to 6 times for women with normal BMI, but it was reduced to 5 after adjustment, indicating the presence of confounding by age and residential area. This correlation has been observed in many other studies as well $(5,10-14)$. According to our results, obesity and overweight in pregnant women are alarming conditions for gestational hypertension. Hence, women who are planning for pregnancy should consider reducing their weight. Furthermore, women should acquire knowledge about the complications of overweightness and obesity in pregnancy.

The risk factors for gestational hypertension identified in various studies are obesity, multiple pregnancies, maternal age over 35 years, race and ethnicity, environmental factors, poverty, and chronic hypertension (6). Elsewhere, other factors have been identified as risk factors for gestational hypertension as well, such as having a history of preeclampsia, low education level, having a sister with a history of preeclampsia, exposure to diethylstilbestrol, interval between current and previous pregnancy, history of preterm delivery, and inadequate prenatal care (6).

In our study, age was also recognized as a risk factor for gestational hypertension. The risk of having gestational hypertension increased by 1.034 times for each year increase in age. These findings are consistent with those of other studies $(3,7,15-16)$. This may be explained by the high rate of fertility in Shadegan's women and the fact that they continue to reproduce until older age.

There was a significant association between a history of gestational hypertension and the risk of gestational hypertension in the current pregnancy. Women with a previous history of gestational hypertension were 10 times more likely to have gestational hypertension than women without any history. This correlation has been observed in many other studies $(6,11,17)$. Given that there is an increased risk of recurrence of gestational hypertension in women who have experienced it before, they should receive more intensive prenatal and pregnancy care.

We also observed a statistically significant association between pregnant women's education and risk of gestational hypertension. Women with high and Secondary school education level had a higher risk of gestational hypertension than women with academic education. However, in studies conducted in Tehran, low maternal education was recognized as a risk factor (6). Zhang et al. found that the risk of hypertension in pregnancy is higher in illiterate and uneducated women 
(10). In another study conducted in Tehran, academic education was identified as a risk factor for hypertensive pregnancy (7). A study conducted in Beijing (15) found no statistically significant association between pregnant women's education and hypertensive pregnancy. Low level of education may be one reason for the lack of sufficient knowledge about the importance of prenatal care in pregnant women's health care. Perhaps, mothers with low education level do not realize the importance of receiving prenatal care. In fact, insufficient perinatal care has been associated with an increased risk of developing gestational hypertension. Given that the results obtained from different studies greatly vary, there is an apparent need to conduct further studies to determine the exact effect of education on the risk of gestational hypertension.

We found no association between the type of residential area and gestational hypertension despite the fact that urbanization is a known risk factor for gestational hypertension in primigravidae, which could be due to differences in lifestyle.

Based on the results of multiple logistic regression, there were no statistically significant associations between gestational hypertension and history of abortion, parity, gravidity, multiple pregnancies, and latest method of contraception used.

Our study had certain limitations. Firstly, it was a casecontrol study, with some inherent limitations compared to prospective studies. Furthermore, as our study was conducted in a certain geographic area, generalization of the findings to other areas should be done with caution. Lastly, we studied different types of gestational hypertension, while the risk factors might have not been exactly the same.

\section{Conclusion}

According to our results, overweightness and obesity are very important risk factors for gestational hypertension in primigravidae and pregnant women in general. Thus, prenatal and perinatal care should be provided to this group of women, with particular attention to the above risk factors. Women should be educated about the complications of obesity and its effects on the risk of gestational hypertension. Moreover, women should adopt a healthy lifestyle and consume healthy foods.

\section{Acknowledgment}

The researchers would like to thank Dr. A Doosti Irani and the officials of Shadegan's health centers.

\section{Conflict of Interests}

The authors declare that they have no competing interests.

\section{References}

1. Antwi E, Klipstein-Grobusch K, Quansah Asare G, Koram KA, Grobbee D, Agyepong IA. Measuring regional and district variations in the incidence of pregnancy-induced hypertension in Ghana: challenges, opportunities and implications for maternal and newborn health policy and programmes. Trop Med Int Health : 2016;21(1):93100 .

2. Cunningham, Leveno, Bloom, Hauth, Rouse, Spong. Williams
Obsterics. 23rd, editor: golban; 2010. 891-935 p.

3. Kichou B, Henine N, Kichou L, Benbouabdellah M. [Epidemiology of pre-eclampsia in Tizi-ouzou city (Algeria)]. Ann Cardiol Angeiol. 2015;64(3):164-8.

4. Mehta B, Kumar V, Chawla S, Sachdeva S, Mahopatra D. Hypertension in Pregnancy: A Community-Based Study. Indian J Community Med: official publication of Indian Association of Preventive \& Social Medicine. 2015;40(4):273-8.

5. Saeed F, Jawad A, Azmat A, Azam I, Kagazwala S. Anthropometric measurements as a risk for hypertensive disorders in pregnancy: a hospital based study in South Asian population. J Pak Med Assoc. 2011;61(1):58-63.

6. Kashanian M, Ali Mohammadi R, Baradaran HRs. Evaluation of Some of the Risk Factors for Preeclampsia. RJMS. 2008;15(59):131-

7. Allahyari E, Rahimi Foroushani A, Zeraati H, Mohammad K, Taghizade Z. A Predictive Model for the Diagnosis of Preeclampsia. J Reprod Infertil -March 2010 10(4):261-7

8. Vahidroodsari F, Ayati S, Ebrahimi M, Esmaily H, Shahabian M. The Effect of Prepregnancy Body Mass Index on the Development of Gestational Hypertension and Preeclampsia. J Babol Univ Med Sci. Oct-Nov 2009;11(4):49-53.

9.pasha.hojjatallah A, pasha.ali A. Ordering in Obstetrics and Gynecology. tehran: GOLBAN; 2014.

10.Zhang JZ, He J. [Risk factors of recurrent preeclampsia and its relation to maternal and offspring outcome]. J Zhejiang Univ Sci B. 2015;44(3):258-63.

11. Harutyunyan A, Armenian H, Petrosyan V. Interbirth interval and history of previous preeclampsia: a case-control study among multiparous women. BMC Pregnancy Childbirth.. $1 r: r \leqslant ; r \cdot 1 r$.

12. Luealon P, Phupong V. Risk factors of preeclampsia in Thai women. J Med Assoc Thai. 2010;93(6):661-6.

13. Ye C, Ruan Y, Zou L, Li G, Li C, Chen Y, et al. The 2011 survey on hypertensive disorders of pregnancy (HDP) in China: prevalence, risk factors, complications, pregnancy and perinatal outcomes. PloS one. 2014;9(6):e100180.

14. Sekkarie A, Raskind-Hood C, Hogue C. The effects of maternal weight and age on pre-eclampsia and eclampsia in Haiti. J. Matern. Fetal. Neonatal. Med. 2016;29(4):602-6.

15. Zhu YC, Yang HX, Wei YM, Zhu WW, Meng WY, Wang YQ, et al. Analysis of correlation factors and pregnancy outcomes of hypertensive disorders of pregnancy - a secondary analysis of a random sampling in Beijing, China. J Matern. Fetal. Neonatal. Med. 2016:1-4.

16. Hu R, Li YX, Di HH, Li ZW, Zhang CH, Shen XP, et al. Risk factors of hypertensive disorders among Chinese pregnant women. J. Huazhong Univ. Sci. Technol. Med. Sci.2015;35:801-7.

17. Lucovnik M, Tul N, Verdenik I, Novak Z, Blickstein I. Risk factors for preeclampsia in twin pregnancies: a population-based matched case-control study. J Perinat Med. 2012;40(4):379-82. 